\title{
Solution Polycondensation of Diesters and Diamines Having Hetero Atom Groups in Polar Solvents
}

\author{
Naoya Ogata, Kohei Sanui, Takeshi Ohtake, \\ and Hiroyuki NAKAMURA \\ Department of Chemistry, Sophia University, \\ 7 Kioi-cho, Chiyoda-ku, Tokyo 102, Japan.
}

(Received May 23, 1978)

\begin{abstract}
Polycondensation reactions of diesters and diamines having hetero atom groups such as ether or hydroxyl groups were carried out in polar solvents such as water and methanol. It was found that hetero atom groups such as ether or hydroxyl groups could greatly enhance the reactivity of diesters when introduced at $\alpha$ or $\beta$ positions on ester carbonyl group, but that they did not change the reactivity of diamines. Polycondensation reactions took place in a methanol solution under mild conditions to form polyamides, while the hydrolysis reaction of the diesters occurred simultaneously with the polycondensation reaction, yielding nylon salts in aqueous solution. The apparent orders of the polycondensation reaction of these diesters with diamines were determined so as to analyze the polycondensation reaction.
\end{abstract}

KEY WORDS Polycondensation / Hydrolysis / Diester / Diamine / Hetero Atom Group /

The polycondensation reactions of ordinary diesters such as dimethyl adipate with diamine are usually carried out under molten conditions at temperatures above the melting point of the resulting polyamides since functional groups such as ester or amino groups do not have sufficient reactivity to allow the reaction to proceed in solutions under mild conditions. Thus, one has to enhance the reactivity of dicarboxylic acids by using acid chloride or active esters in order to carry out the polycondensation reaction under mild conditions.

It was previously found ${ }^{1.2}$ that the reactivity of diesters was greatly enhanced to such extent that polycondensation with diamines proceeded in solutions even at room temperature when hetero atom groups such as ether or hydroxyl groups were introduced onto the diesters. Thus, dimethyl tartrate, ${ }^{3}$ dimethyl mucate, ${ }^{4}$ which is tetrahydroxyl adipate, or diesters having ether or thioether groups ${ }^{5}$ could react with diamine in solution under mild conditions to yield corresponding polyamides. The active polycondensation of these diesters was strongly dependent on the polarity of the solvents and no apparent equilibrium of the polycondensation existed.
In this paper, the polycondensation reactions of these diesters having hetero atom groups has been carried out in strong polar solvents such as water or methanol to investigate the reactivity change in the diesters with diamines resulting from the polarity effect of the reaction medium. Moreover, the reactivity change of amino group of diamine by introducing hetero atom groups has also been investigated.

\section{EXPERIMENTAL}

\section{Materials}

Diesters Having Hetero Atom Groups. Diethyl esters of commercially available tartaric acid or mucic acid were prepared by conventional esterification in ethanol.

Diethyl tartrate $\operatorname{EtOOC}(\mathrm{CH})_{2} \mathrm{COOEt}(\mathrm{DET})$,
$\mathrm{OH}$

bp $126^{\prime \prime} \mathrm{C} /[3 \mathrm{mmHg}(0.4 \mathrm{kPa})]$

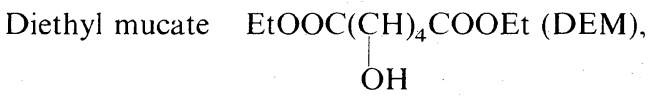
mp $161^{\prime \prime} \mathrm{C}$. 
4,5-dimethoxycarbonyl-1,3-dioxolane (DMOC) was prepared by reacting dimethyl tartrate with trioxane in the presence of sulfuric acid. ${ }^{6}$

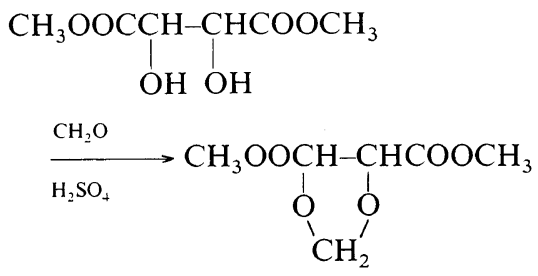

DMOC, bp $118^{\circ} \mathrm{C} /[4 \mathrm{mmHg}(0.53 \mathrm{kPa})]$

Dimethyl ethylenedioxydiacetate (EOAc) was synthesized by the oxidation of triethyleneglycol with nitric acid, followed by esterification with methanol. ${ }^{7}$

$$
\mathrm{HOCH}_{2} \mathrm{CH}_{2} \mathrm{OCH}_{2} \mathrm{CH}_{2} \mathrm{OCH}_{2} \mathrm{CH}_{2} \mathrm{OH}
$$

$\mathrm{HNO}_{3} \longrightarrow \mathrm{HOOCCH}_{2} \mathrm{OCH}_{2} \mathrm{CH}_{2} \mathrm{OCH}_{2} \mathrm{COOH}$

$\stackrel{\mathrm{CH}_{3} \mathrm{OH}}{\longrightarrow} \mathrm{CH}_{3} \mathrm{OOCCH}_{2} \mathrm{OCH}_{2} \mathrm{CH}_{2} \mathrm{OCH}_{2} \mathrm{COOCH}_{3}$

$$
\text { EOAc, bp } 121^{\circ} \mathrm{C} /[6 \mathrm{mmHg}(0.8 \mathrm{kPa})]
$$

Diamine Having Ether Group. Bis(3-aminopropyl) ether was obtained by the catalytic reduction of bis(2-cyanoethyl) ether in ethanol under 150 atomsphere pressure of hydrogen in the presence of Raney Cobalt.

$$
\begin{gathered}
\mathrm{NCCH}_{2} \mathrm{CH}_{2} \mathrm{OCH}_{2} \mathrm{CH}_{2} \mathrm{CN} \\
\stackrel{\mathrm{H}_{2}}{\longrightarrow} \mathrm{NH}_{2}\left(\mathrm{CH}_{2}\right)_{3} \mathrm{O}\left(\mathrm{CH}_{2}\right)_{3} \mathrm{NH}_{2}
\end{gathered}
$$

APrE, bp $50^{\circ} \mathrm{C} /[0.3 \mathrm{mmHg}(40 \mathrm{~Pa})]$

3-Ethylenedioxybis(1-aminopropane) (EOPr) was obtained by the same method of the catalytic reduction of 3-ethylenedioxydipropiononitrile.

$$
\begin{aligned}
& \mathrm{NCCH}_{2} \mathrm{CH}_{2} \mathrm{OCH}_{2} \mathrm{CH}_{2} \mathrm{OCH}_{2} \mathrm{CH}_{2} \mathrm{CN} \\
& \stackrel{\mathrm{H}_{2}}{\longrightarrow} \mathrm{NH}_{2}\left(\mathrm{CH}_{2}\right)_{3} \mathrm{OCH}_{2} \mathrm{CH}_{2} \mathrm{O}\left(\mathrm{CH}_{2}\right)_{3} \mathrm{NH}_{2}
\end{aligned}
$$

EOPr, bp $79^{\circ} \mathrm{C} /[0.2 \mathrm{mmHg}(27 \mathrm{~Pa})]$

\section{Polycondensation Reaction}

The polycondensation reactions of diesters with diamines, which have hetero atom groups, were carried out in methanol or water at a given con- centration at $30^{\circ} \mathrm{C}$. The rates of polycondensation were determined by titrating residual amounts of amino group with $0.1 \mathrm{~N} \mathrm{HCl}$ in the presence of $p$ nitrophenol as a $\mathrm{pH}$ indicator after a given time of reaction.

\section{Analyses of Reaction Products}

Products obtained by the reaction of the diesters with diamine in solutions were isolated by evaporating solvents in vacuum at room temperature, followed by washing with acetone and drying. The products obtained were analyzed by the following methods.

(1) Infrared Spectrum It was measured by a $\mathrm{KBr}$ pellet method.

(2) NMR It was measured in heavy water at $35^{\circ} \mathrm{C}$ by the Hitachi Model R-22.

(3) Paper Chromatography Toyo filter paper No. 50 was used with a mixed solvent of butyl alcohol-concd ammonia-ethylene glycol= 85:15: 5 as a developer.

(4) Liquid Chromatography A high-speed liquid chromatography, (Waters Model 440), was used with a column of $\mu \mathrm{C}_{18}(\mathrm{P} / \mathrm{N} 27386)$ at a flow rate of $10 \mathrm{~mm} / \mathrm{min}$ of water as the solvent.

(5) Molecular Weight It was determined in water by a vapor pressure osmometer.

\section{Hydrolysis of Diesters}

Diesters were hydrolyzed in an aqueous solution of sodium hydroxide at $\mathrm{pH}=12$ at $30^{\circ} \mathrm{C}$. The $\mathrm{pH}$ of the aqueous solution was adjusted to the same $\mathrm{pH}$ of the aqueous solution of hexamethylenediamine at a concentration of $0.1 \mathrm{~mol} \mathrm{dm}^{-3}$. Hydrolysis reaction rates were determined by the amount of liberated alcohols, using gas chromatography with a column of Prapak S.

\section{RESULTS AND DISCUSSION}

\section{Polycondensation of Diesters Having Hetero Atom Groups with Hexamethylenediamine (HMD)}

The polycondensation reactions of various diesters having ether or hydroxyl groups with HMD were carried out in water or methanol and the results are shown in Figures 1 and 2, respectively. The reaction rate of DEM, which has four hydroxyl groups, was the fastest among the diesters and the apparent rates of the reaction could be arranged either in water or methanol as follows: DEM > 


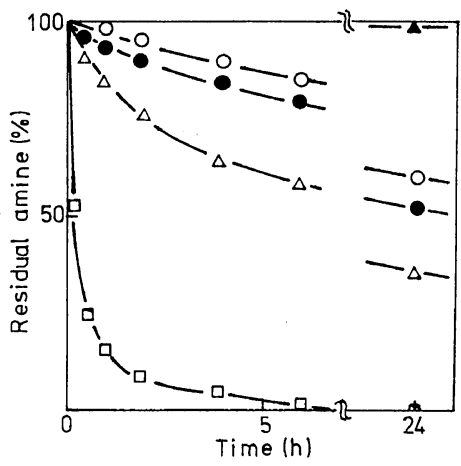

Figure 1. Polycondensation of various diesters with HMD in methanol at $30^{\circ} \mathrm{C}$ : monomer concn $=1 \mathrm{~mol}$ $\mathrm{dm}^{-3} ;(\square), \mathrm{DEM} ;(\triangle)$, DMOC; $(\odot)$, EOAc; (O), DET; (A), DMA.

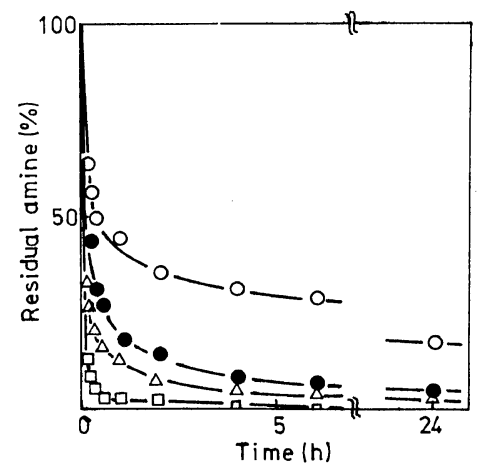

Figure 2. Polycondensation of various diesters with $\mathrm{HMD}$ in water at $30^{\circ} \mathrm{C}$ : monomer concn $=1 \mathrm{~mol} \mathrm{dm}^{-3}$; $(\square)$ DEM; $(\triangle)$, DMOC; $(\bigcirc)$, EOAc; (O), DET.

DMOC $>$ EOAC $>$ DET $\gg$ DMA (dimethyl adipate).

The reaction of these diesters with HMD in water proceeded much faster than that in methanol, as can be seen from Figure 1 with Figure 2. The reaction of EOAc with HMD was carried out in a mixed solvent with various mixing ratios of methanol and water and the results are summarized in Figure 3. As expected, increasing the amount of water increased the apparent reaction rate. The paper chromatography of the reaction products obtained from DEM or EOAc with HMD in water or aqueous methanol, indicated a spot of $R f=0.75$ which was consistent with the $R f$ value of nylon salts from corresponding dicarboxylic acid and HMD. The molecular weight of the reaction products from DEM and HMD was 2,000, while that from EOAc and HMD was 220.

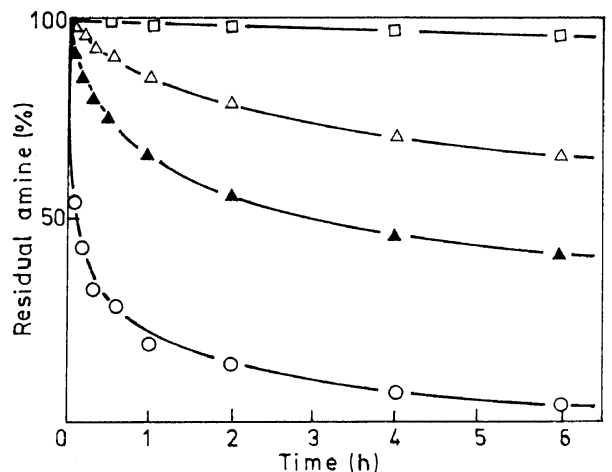

Figure 3. Reaction of EOAc with HMD in a mixed solvent of methanol and water at $30^{\circ} \mathrm{C}$ : monomer co$\mathrm{ncn}=0.01 \mathrm{~mol} \mathrm{dm}{ }^{-3} ; \quad(\mathrm{O}), \mathrm{H}_{2} \mathrm{O} ; \quad(\boldsymbol{\Delta}), \mathrm{H}_{2} \mathrm{O} /$ $\mathrm{CH}_{3} \mathrm{OH}=5 / 5 ;(\triangle), \mathrm{H}_{2} \mathrm{O} / \mathrm{CH}_{3} \mathrm{OH}=2 / 8 ;(\square), \mathrm{CH}_{3} \mathrm{OH}$.

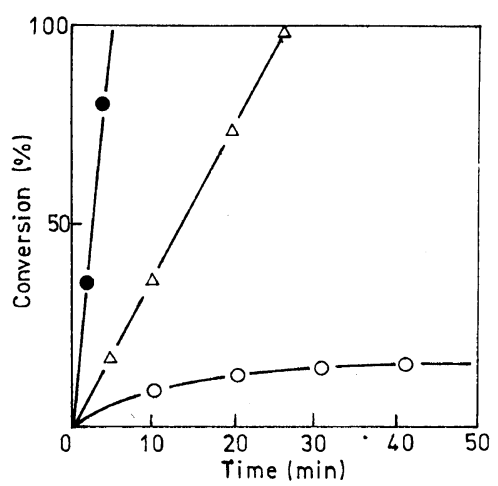

Figure 4. Hydrolysis reaction of various diesters in an aqueous solution of $\mathrm{NaOH}$ at $30^{\circ} \mathrm{C}$ : concn of diesters $=0.1 \mathrm{~mol} \mathrm{dm}^{-3}$ initial $\mathrm{pH}=12 ;(\bigcirc)$, DET; $(\triangle)$, DEM; (O), EOAc.

These results suggested that the reaction in an aqueous system might be accompanied with a side reaction, i.e., the hydrolysis of the diesters into dicarboxylic acids, which eventially formed nylon salts with HMD. The rapid reaction of the diesters in aqueous solution is apparently the sum of the polycondensation and the hydrolysis reactions.

In order to compare the competitive hydrolysis reaction with the polycondensation, a hydrolysis reaction of the diesters was carried out in an aqueous solution of sodium hydroxide at $\mathrm{pH}=12$ which was the same $\mathrm{pH}$ value of the HMD solution of 0.1 mol dm ${ }^{-3}$. Results are indicated in Figure 4, where it can be seen that DET and DEM are subjected much more rapidly to the hydrolysis reaction than is EOAc. 
The reaction products of these diesters with HMD in aqueous solution were analyzed by NMR and liquid chromatography, and the ratios of the polycondensation and the hydrolysis reactions were determined by measuring peak intensities corresponding to polyamide and nylon salt. The results are summarized in Table I where the ratios between the hydrolysis and the polycondensation reactions are shown to increase with decreasing concentration in the diesters and HMD, and only the hydrolysis reaction of the diesters took place in a diluted solution without the formation of polyamides, because the hydrolysis reaction preceeds the polycondensation reaction in aqueous phase. On the other hand an increasing amount of methanol in the aqueous solution increased the extent of the polycondensation reaction yielding polyamide; polyamide was exclusively formed in $100 \%$ methanol solution.

As previously mentioned, diesters having hydroxyl group such as DEM or DET were easily hydrolyzed at a much faster rate than EOAc which has ether groups. Nevertheless, DEM and DET yielded to some extent polyamide in aqueous solution, while EOAc produced mainly nylon salt in aqueouss solution, as seen from the results of Table I and from the molecular weights of the reaction products. This may be due to the great reactivity of hydroxyl diesters toward the nucleophilic attack of HMD, permiting formation of polyamide even in aqueous solution.

\section{Polycondensation of Diesters with Diamines Having Ether Group}

Polycondensation reactions of various diesters with diamines having ether groups were carried out in methanol at $30^{\circ} \mathrm{C}$ and the results are indicated in Figures 5, 6, and 7, respectively. Comparing the results of polycondensation reactions indicated in Figure 1 with HMD with those in Figures 5, 6, 7, it can be seen that the reactivity enhancement for the polycondensation reactions of diesters with diamines were caused primarily by the introduction of hetero atom groups onto diesters but no acceleration effect could be observed when such groups were in-

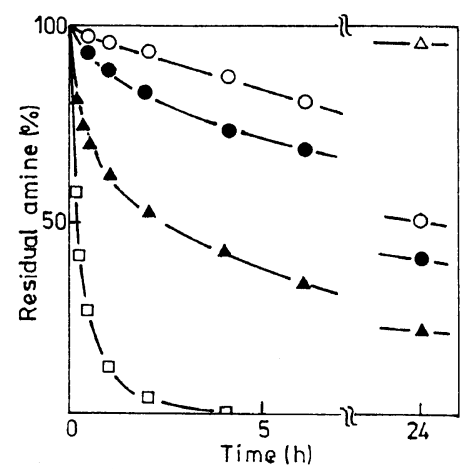

Figure 5. Polycondensation of various diesters with APrP in methanol at $30^{\circ} \mathrm{C}$ : monomer concn $=0.1 \mathrm{~mol}$ $\mathrm{dm}^{-3} ;(\square), \mathrm{DEM} ;(\mathbf{\Delta}), \mathrm{DMOC} ;(\boldsymbol{O}), \mathrm{EOAc} ;(\bigcirc), \mathrm{DET}$; $(\triangle)$, DMA.

Table I. Ratios of polyamides and nylon salts in the polycondensation of diesters in aqueous solution ${ }^{\mathrm{a}}$

\begin{tabular}{|c|c|c|c|c|}
\hline \multirow{2}{*}{ Diester } & \multirow{2}{*}{ Solvent } & \multirow{2}{*}{$\begin{array}{l}\text { Monomer } \\
\text { concn/ } \\
\text { mol dm }\end{array}$} & \multicolumn{2}{|c|}{ Product ratios $/ \mathrm{mol}^{\mathrm{o}} \%{ }^{\mathrm{b}}$} \\
\hline & & & Polyamide & Nylon salt \\
\hline \multirow[t]{8}{*}{ DEM } & $\mathrm{H}_{2} \mathrm{O}$ & 0.01 & 0 & 100 \\
\hline & " & 0.03 & 14 & 86 \\
\hline & " & 0.05 & 20 & 80 \\
\hline & " & 0.10 & 31 & 69 \\
\hline & \multicolumn{4}{|l|}{$\mathrm{H}_{2} \mathrm{O} / \mathrm{CH}_{3} \mathrm{OH}=$} \\
\hline & $50 / 50$ & 0.10 & 40 & 60 \\
\hline & $20 / 80$ & 0.10 & 75 & 25 \\
\hline & $\mathrm{CH}_{3} \mathrm{OH}$ & 0.10 & 100 & 0 \\
\hline DET & $\mathrm{H}_{2} \mathrm{O}$ & 0.10 & 5 & 95 \\
\hline \multirow[t]{3}{*}{ EOAc } & $\mathrm{H}_{2} \mathrm{O}$ & 0.01 & 0 & 100 \\
\hline & $"$ & 0.05 & 6 & 94 \\
\hline & " & 0.10 & 13 & 87 \\
\hline
\end{tabular}

a Diesters were allowed to react with $\mathrm{HMD}$ at $35^{\circ} \mathrm{C}$.

b Estimated by NMR. 


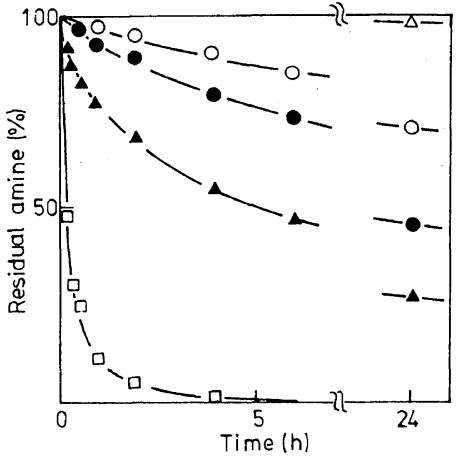

Figure 6. Polycondensation of various diesters with APrE in methanol at $30^{\circ} \mathrm{C}$ : monomer concn $=0.1 \mathrm{~mol}$ $\mathrm{dm}^{-3} ;(\square), \mathrm{DEM} ;(\boldsymbol{\Lambda}), \mathrm{DMOC} ;(\boldsymbol{O}), \mathrm{EOAc} ;(\bigcirc), \mathrm{DET}$; $(\triangle)$, DMA.

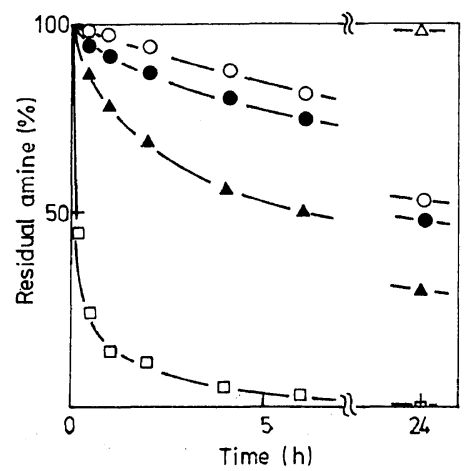

Figure 7. Polycondensation of various diesters with EOPr in methanol at $30^{\circ} \mathrm{C}$ : monomer concn $=0.1 \mathrm{~mol}$ $\mathrm{dm}^{-3} ;(\square), \mathrm{DEM} ;(\boldsymbol{\Delta}), \mathrm{DMOC} ;(\boldsymbol{O}), \mathrm{EOAc} ;(\bigcirc), \mathrm{DET}$; $(\triangle)$ DMA.

troduced onto the diamines. In other words, the apparent polycondensation reaction rates of diesters with diamines containing ether groups were similar to the polycondensation reaction rates with HMD in the following reactivity order:

$$
\mathrm{DEM}>\mathrm{DMOC}>\mathrm{EOAC}>\mathrm{DET} \gg \mathrm{DMA}
$$

Thus, in summary, hetero atom groups such as ether or hydroxyl groups can enhance the reactivity only of diesters toward diamines, but there is no change in reactivity of diamines toward diesters.

\section{Kinetic Analysis of the Polycondensation}

Apparent rate constants for polycondensation reactions in combination with various diesters and diamines were calculated on the assumption that the reactions proceeded according to second-order reaction mechanisms at the initial stage; the results are summarized in Table II.

It is clearly seen from Table II that the enhancement effect of the hetero atom groups on the reactivity of diesters or diamines is considerable, but only when these groups are introduced onto the diesters. The polycondensation of diesters having hydroxyl groups proceeded by second-order reaction mechanisms. On the other hand, the polycondensation of diesters having ether or formal groups took place by reaction mechanisms of a higher order than for second-order reactions following the initial stage of the polycondensation.

It was presumed in a previous paper ${ }^{8}$ that the enhancement effect of hetero atom groups on the reactivity of diesters could be ascribed to interactions such as hetero atom groups with approaching amine, as an hydrogen bonding, so that a local concentration of amines near diester molecules is increased, since there was no polarity change in the ester carbonyl group observed by ${ }^{13} \mathrm{C}$ NMR spectrum. However, the polycondensation reaction of

Table II. Apparent rate constants of the polycondensation for various diester and diamine combinations in methanol at $30^{\circ} \mathrm{C}^{\mathrm{a}}$

\begin{tabular}{lllll}
\hline & & \multicolumn{3}{c}{ Diamine } \\
\cline { 2 - 5 } & \multicolumn{1}{c}{ APrA } & APrE & EOPr & HMD \\
\hline DEM & 6.0 & 7.8 & 8.6 & 9.2 \\
DMOC & 3.8 & 1.6 & 0.8 & 0.43 \\
EOAc & 0.33 & 0.17 & 0.23 & 0.13 \\
DET & $7.3 \times 10^{-2}$ & $5.7 \times 10^{-2}$ & $8.9 \times 10^{-2}$ & $6.5 \times 10^{-2}$ \\
DMA & $1.0 \times 10^{-3}$ & $4.5 \times 10^{-4}$ & $4.5 \times 10^{-4}$ & $4.5 \times 10^{-4}$ \\
\hline
\end{tabular}

a $\mathrm{dm}^{3} \mathrm{~mol}^{-1} \mathrm{~h}^{-1}$. 
Table III. Physical properties of polyamides having hetero atom groups

\begin{tabular}{|c|c|c|c|c|c|c|c|c|c|c|}
\hline \multirow{2}{*}{ Polyamide } & \multicolumn{2}{|c|}{ Thermal property ${ }^{\mathrm{a}}$} & \multirow{2}{*}{$\eta_{\mathrm{sp}} / c^{\mathrm{b}}$} & \multicolumn{7}{|c|}{ Solubility } \\
\hline & $T_{\mathrm{m}} /{ }^{\circ} \mathrm{C}$ & $T_{\mathrm{d}} /{ }^{\circ} \mathrm{C}$ & & $\mathrm{H}_{2} \mathrm{O}$ & $\mathrm{MeOH}$ & $\mathrm{DMSO}^{\mathrm{c}}$ & $D_{M A c^{d}}$ & $\mathrm{CHCl}_{3}$ & $\mathrm{BzOH}^{\mathrm{e}}$ & $m-\mathrm{Cre}^{\prime}$ \\
\hline DEM-APrA & - & 172 & 0.08 & + & - & + & - & - & - & - \\
\hline APrE & - & 185 & 0.23 & - & - & + & - & - & + & + \\
\hline EOPr & - & 180 & 0.11 & + & - & + & - & - & + & + \\
\hline HMD & - & 202 & 0.18 & - & - & - & - & - & - & - \\
\hline DET-APrA & - & 172 & 0.05 & - & - & + & + & - & + & + \\
\hline APrE & 120 & 182 & 0.16 & - & - & + & - & - & + & + \\
\hline EOPr & 180 & 224 & 0.08 & + & - & + & - & - & + & + \\
\hline HMD & - & 215 & 0.21 & - & - & - & - & - & - & + \\
\hline DMOC-APrA & 84 & 200 & 0.02 & + & + & + & + & - & + & + \\
\hline APrE & 50 & 270 & 0.05 & + & + & + & + & - & + & + \\
\hline EOPr & - & 265 & 0.05 & + & + & + & + & + & + & + \\
\hline HMD & 40 & 190 & 0.14 & - & + & + & + & - & + & + \\
\hline EOAC-APrA & 120 & 254 & 0.04 & + & + & + & + & - & + & + \\
\hline APrE & - & 242 & 0.04 & + & + & + & + & + & + & + \\
\hline EOPr & - & 252 & 0.04 & + & t & + & + & - & + & + \\
\hline HMD & 96 & 210 & 0.06 & + & + & + & + & + & + & + \\
\hline
\end{tabular}

${ }^{a}$ Measured by DTA and TGA.

${ }^{b}$ Measured in sulfuric acid at $30^{\circ} \mathrm{C}$.

${ }^{c}$ Dimethylsulfoxide.

d Dimethylacetamide.

e Benzyl alcohol.

f $m$-Cresol.

these hetero diesters with diamines occurs rapidly in polar solvents such as methanol or water which do not favor the formation of the hydrogen bonds. The apparent higher reaction orders of the polycondensation reactions for these hetero diesters in polar solvents suggest that the reactions may not proceed through simple molecular collision after a certain period of the reaction time in view of the fact that the reactions did not follow the second-order mechanisms. These reactions may involve more complicated mechanims at the intermediate reaction stage. The acceleration effect of these hetero atom groups may be ascribed to both intra- and intermolecular interactions between ester and amino groups as follows.

Intramolecular interaction

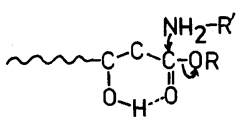

Intermolecular interaction

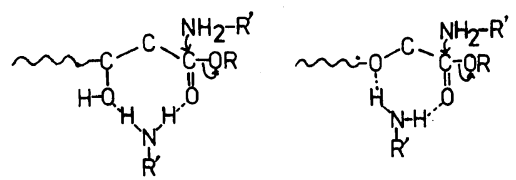

These interactions may facilitate the approach of an amine to an ester carbonyl group even in polar solvents resulting in an amide linkage. The apparent higher reaction orders may be related to reaction intermediates formed at the transition stage of the reaction, forming amide linkages.

\section{Properties of Polyamides}

The physical properties of polyamides obtained under mild conditions are summarized in Table III. Polyamides were obtained in good yield, but the solution viscosities of these polyamides were not satisfactorily high. The apparent low solution viscosities of resulting polyamides may be due perhaps to incomplete reaction of polymer chains to become longer, as a result of entanglements brought on by polar hetero atom groups. Solution viscosities could be improved by raising reaction temperatures up to $150^{\circ} \mathrm{C}$. 
Most of the polyamides had no distinct melting points and started to decompose when heated above $200^{\circ} \mathrm{C}$, presumably owing to the poor thermal stability of the hetero atom groups. The solubility of the polyamides was fairly good in common organic solvents such as methanol because of the presence of polar hetero atom groups on the polymer chains.

Acknowledgement. The authors wish to express their gratitude to Dr. Watanabe of the Research Institute for Polymers and Textiles for providing molecular weight measurements of the polyamides.

\section{REFERENCES}

1. N. Ogata, K. Sanui, and K. Ohkouchi, Polym. J., 5, 186 (1973).

2. N. Ogata and Y. Hosoda, J. Polym. Sci., Polym. Lett. Ed., 12, 355 (1974).

3. N. Ogata and Y. Hosoda, J. Polym. Sci., Polym. Chem. Ed., 13, 1973 (1975).

4. N. Ogata, K. Sanui, Y. Hosoda, and H. Nakamura, $J$. Polym. Sci., Polym. Chem. Ed., 14, 783 (1976).

5. N. Ogata and K. Shimamura, Polym. J., 7, 72 (1975).

6. N. Ogata and Y. Hosoda, J. Polym. Sci., Polym. Lett. Ed., 14, 409 (1976).

7. British Patent 639, 491 (1950).

8. N. Ogata, K. Sanui, and H. Nakamura, Polym. J., 10, 499 (1978). 